\title{
Aesthetic Categories of Interaction: Aesthetic Perceptions on Smartphone and Computer
}

\author{
Mati Mõttus \\ Tallinn University \\ Narva mnt 29, Tallinn \\ Estonia \\ Email: matim@tlu.ee
}

\author{
David Lamas \\ Tallinn University \\ Narva mnt 29, Tallinn \\ Estonia \\ Email: drl@tlu.ee
}

\author{
Liina Kukk \\ Tallinn University \\ Narva mnt 29, Tallinn \\ Estonia \\ Email: liinaku@tlu.ee
}

\begin{abstract}
Experiential attributes are a possible way of explaining user's experiences during interaction. Recently presented set of 23 aesthetic categories of interaction was established with a purpose to explain users' aesthetic experiences. This recent work focused on touch devices, such as smartphones and tablets, and concluded with the need to study further the goodness of established categories. The study, reported in this paper, continues to explore the consistency and aesthetic relations of these categories by comparing their goodness in explaining aesthetic perceptions on different devices: a smartphone and a laptop computer. Experimental research design with $2 \times 2$ conditions was used. Two of the conditions consisted of completing the same interaction episode on two different devices. The other two conditions consisted of passive watching the screen recordings of previous interactions on the same two devices. In conclusion, the aesthetic categories of interaction were found capable of explaining users perceptions across devices, but further study was suggested.
\end{abstract}

\section{INTRODUCTION}

A RECENT study by Mõttus et al. explored users' aesthetic perceptions during interaction [20]. This study used repertory grid technique (RGT) to elicit total number of 134 personal constructs, which were then sorted into 23 aesthetic categories of interaction (ACI). Quantitative data from RGT allowed to assess inner consistency and aesthetic correlation of established categories. Not all of these categories were proved consistent and neither did all of them show significant aesthetic correlations. Low inner consistency and aesthetic correlation in case of some categories may occur due to a low number of evaluations per category (ranging from 1 to 10) during the RGT study. This study reported numerous overlappings, which were found between experiential attributes, established earlier by other similar studies e.g., [12], [13], [14], [6], [19], and the newly established categories. Recurrence of similar items in various occasions suggests not to reject inconsistent categories but test them again in various context. In conclusion, further studies were proposed with different stimuli, different sample of participants and different situation of use. Following general research questions were posed to find out more about the goodness of aesthetic categories of interaction.

1. How consistently do users perceive aesthetic categories of interaction?

2. How capable are given categories of explaining users aesthetic perceptions during the interaction?

- Whether the categories are capable of explaining users' aesthetic perceptions?

- Whether the categories are capable of distinguishing aesthetics of interaction and aesthetics of appearance?

Current study deploys the data, collected during a user testing of the Estonian Tourist Information website, http://visitestonia.com with two different types of devices, computer and smart phone [9].

\section{RELEVANT WORKS}

This study is focused on aesthetics of interaction, defined through the products that feel beautiful in use [1]. The beauty of use is often obscured by the beauty of appearance, a phenomenon that still earns researchers' major attention on field of HCI [17], [24], [15], [18], [25]. However, the beauty of use begins to gain more attention in light of gradual changes towards novel ways of interaction. Daily-use interfaces have become more multimodal when compared to traditional PC setups with mouse, keyboard and monitor. Modern interactions require at least three of our senses (sight, hearing and touch) for perceiving system reactions as well as completing user actions. The extremely popular mobile and tablet devices are accompanied by solutions of distributed interfaces (e.g., public displays, accessible from personal devices), smart home technology (e.g., smart TV, smart car), wearable physiological equipment (e.g., medical health monitors, sports trackers) and more. There has opened much wider scope of user experiences (UX), suggesting a good reason to study the aesthetics of interaction more closely.

\section{A. Aesthetics of interaction}

Aesthetics of interaction was first mentioned in designrelated studies and theoretical discussions in the beginning of 2000's. Hallnäs and Redström describe aesthetics of interaction as a phenomenon to be considered in pleasureoriented design approach called slow technology [2]. The authors of this study believed that certain dynamics, both physical and mental, afford additional perception of pleasure in otherwise pragmatic interactions. Further, Djajadiningrat et 
al. introduce the term beauty of use while analysing the design cases of tangible interactions [1]. During a discussion about the principles of pleasurable design, Hekkert argues whether our aesthetic experiences are limited only to the pleasure from sensory perception [7]. The discussion continues by narrowing down the notion of beauty to visual perception, as it may better correspond to laypersons' understanding [5]. These thoughts are further developed in Löwgren's five beliefs about aesthetics in interaction design [16]. Three of these beliefs seem to be more relevant for current study. First, genre determines the aesthetic qualities; second, it makes little sense to talk about visual aesthetics as an isolated modality; and third, aesthetic experience is connected with intellectual deliberation as much as with immediate, visceral response. Altogether these works contribute to the understanding of aesthetics in interaction, while also contradicting each other in some aspects. One of such aspects is multimodality of aesthetics. Current study will handle aesthetics as a multimodal experiences, i.e., perceived by all senses, and processed through intellectual deliberation. Multimodality of senses has been addressed by a relatively small number of previous studies in HCI. Those works concern senses of sight, hearing and touch. Aesthetics of sound has been mentioned in connection with sonic system reaction in interaction design by Rocchesso et al. [22]. Aesthetic framework of touch for tactile interactions has been proposed by Shiphorst et al. [23]. This last work refers to Laban effort theory [10] when explaining the aesthetics of gestures and interface dynamics. The design of graceful movements during the interaction is more thoroughly covered in series of works by Hashim et al. [26], [4], [3], [21]. Beauty of dynamics and grace of the movements has become more relevant in context of growing popularity of gesture-based interactive devices.

\section{B. Aesthetics Categories of Interaction}

A recent study was conducted to understand users aesthetic perceptions during interaction with touch devices, such as smart phones and tablets [20]. This study deployed RGT to elicit aesthetic constructs directly from users. The elicitation process used nine short interaction episodes as stimuli. These episodes were carefully selected to provide possibly diverse UX. Participants were asked to try out stimuli and provide the reasons why these stimuli were either beautiful or ugly. Participants were also instructed to focus on beauty of interactions and avoid the beauty of appearance. All together 21 participants succeeded of eliciting 134 personal constructs. Finally, 23 aesthetic categories of interaction (ACI) (shown in TableI) were established as a result of grouping the personal constructs by similarity. Authors believed the use of lay people in elicitation process could add new aspects to the body of earlier work. The attributes, established in earlier similar studies were elicited using experts e.g., [13], or theories [19] of aesthetics or UX.

\section{Attributes of $U X$}

The context of previously established experiential attributes of interaction is different across these works. Following list of most distinct examples varies from the visual aesthetics of websites to the UX in industrial design: visual aesthetics of website's graphical layout [19], visually perceived aesthetics of website interactions [12], aesthetic-related features of websites' interactions [14], UX-related features of industrial interaction design [13] and general UX [6]. Yet, many similar items appear across different sets of attributes from different studies in various context. After ACI were established within the context of touch devices (smart phones and tablets), authors found 15 out of 23 categories to be similar to the ones across earlier works: Hassenzahl et al. [6] (playfulness, fashion, personal relatedness, complexity and predictability), Lim et al. [14] (speed, delay, synaesthesia, smooth phrasing and range) and Lenz et al. [13] (precision, predictability, controllability, speed, delay, smooth mechanics, force,

TABLE I.

AESTHETIC CATEGORIES OF INTERACTION WITH CORRESPONDING SEMANTIC DIFFERENTIALS.

\begin{tabular}{|l|l|}
\hline & Aesthetic Category of Interaction \\
\hline 1 & Arousal: exciting / calm \\
\hline 2 & Playfulness: playful / serious \\
\hline 3 & Dynamics: dynamic / static \\
\hline 4 & Fashion: modern / old fashioned \\
\hline 5 & Natural realism: natural / unnatural \\
\hline 6 & Precision: precise / imprecise \\
\hline 7 & Congruence: appropriate / inappropriate \\
\hline 8 & Informativeness: informative / arbitrary \\
\hline 9 & Personal relatedness: fits me / doesn't fit me \\
\hline 10 & Closure: complete / incomplete \\
\hline 11 & Complexity: complex / simple \\
\hline 12 & Predictability: predictable / unpredictable \\
\hline 13 & Controllability: controlled / uncontrolled \\
\hline 14 & Time/Speed: fast / slow \\
\hline 15 & Delay: immediate / delayed \\
\hline 16 & Synaesthesia: synchronized / unsynchronized \\
\hline 17 & Smooth mechanics: continuous / stepwise \\
\hline 18 & Smooth phrasing: flowing / dripping \\
\hline 19 & Force: powerful / gentle \\
\hline 20 & Proximity: close / distant \\
\hline 21 & Smooth texture: smooth / rough \\
\hline 22 & Range: free / limited \\
\hline 23 & Dimensionality: 3D / 2D \\
\hline & \\
\hline
\end{tabular}


proximity). Additionally, the category of dynamics is found among the aspects of visual aesthetics by Moshagen [19] and arousal is similar to fascination by Lavie and Tractinsky [12]. Not all of the discussed attributes are stricktly connected to the aesthetics of interaction, however, they all express various users' experiences through the features of design. For example Hassenzahl et al. describe experiential attributes in 4 groups, each related to a certain type of user needs: pragmatic, hedonic stimulation, hedonic identification and attractiveness. Some of the discussed attributes express the goodness of design, for example, symmetrical visual design is generally considered more pleasing [12] and visually complex interfaces are generally perceived less pleasing [19]. Other attributes may well describe the experiences, but do not necessarily express the goodness of design. For example, the attribute stepwise vs fluent [13] can not be explicitly related to either good or bad design. However, specific context may make users to prefer one or another end of the scale. For example users tended to be more pleased with predictable course of interactions in pragmatic situation (like sending an email), while predictable interactions during a situation of game were often felt less pleasurable and rather boring. In such a way, the context of use determines relations between the attributes and the quality of interactions. A sequence of studies by Karapanos et al. focuses on four sources of diversity in UX: individual, product, situation and time [8]. Awareness of these four sources would help to specify the conditions for more or less homogeneous UX. When looking at the analysis of goodness of ACI [20], the diversity of UX was mainly accounted through the product, i.e., an interaction episode on a specific device. Individuals were chosen from lay people and the situation was not accounted, except the purpose of use, as the episodes could have been recognized either pragmatic or leisure-related. Time was determined by the duration of interaction episodes which were considerably short and more or less similar, e.g., tap to select a menu item or slide to scroll the page.

Unlike in elicitation study of ACI, the longer interaction episodes may not be as easy to analyse. Different actions and reactions in sequence may cause various aesthetic perceptions, resulting eventually in experiences that are difficult to attribute to any particular feature of design. Therefore authors seeked for a way of describing common elementary interactions. User actions for mobile and tablet devices could be described according to the list of touch efforts in a conceptual framework for understanding the aesthetic qualities of multi-touch and tactile interfaces, proposed by Schiphorst et al. [23] (e.g., tap, hold, glide). System reactions were described in two ways. First as a description of interaction mechanics according to attributes of interactivity by Lim et al. [14] (e.g., slowly, concurrently, instantly), and secondly through the user's pragmatic intentions (e.g., to select menu items, to scroll the view). Authors believe the consideration of elementary descriptions of user actions and system reactions may help to attribute the aesthetic experience during a longer sequence of interactions.

\section{STUDY}

\section{A. $\quad$ Method}

The study used experimental design with four conditions. The conditions were applied through the stimuli — an interaction episode on tourist information website. Two of the conditions concerned interactive devices, a computer and a smart phone were used to test the completion of the same task. The other two conditions distinguished aesthetics of appearance from aesthetics of interaction: a short video of interface and a hands on interactive task were used on both types of devices. The participants were asked to test all 4 conditions and empirical data were collected immediately after each condition (stimulus).

Answering the research questions required the data about perceived aesthetics of interaction and perceptions on the scales, based on ACI. Corresponding semantic differentials, which were planned to use as scales are listed in the TableI. Two instruments were considered in order to evaluate aesthetics of interaction: the attractiveness facet in AttrakDiff questionnaire [6] and similar facet in User Experience Questionnaire (UEQ) [11]. The items of both questionnaires are listed in TableII. We identified 2 items in each instrument, which do not directly express aesthetic judgement: bad-good, discouraging-motivating and friendly-unfriendly (emphasized in TableII). Five relevant items in AttrakDiff questionnaire

TABLE II.

COMPARISON OF ATTRACTIVENESS-RELATED ITEMS IN ATTRAKDIFF AND UEQ QUESTIONNAIRES.

\begin{tabular}{|l|l|}
\hline \multicolumn{2}{|c|}{ AttrakDiff } \\
\hline 1 & unpleasant / pleasant \\
\hline 2 & ugly / attractive \\
\hline 3 & disagreeable / likeable \\
\hline 4 & rejecting / inviting \\
\hline 5 & bad / good \\
\hline 6 & repelling / appealing \\
\hline 7 & discouraging / motivating \\
\hline & \multicolumn{2}{|c|}{ UEQ } \\
\hline 1 & annoying / enjoyable \\
\hline 2 & good / bad \\
\hline 3 & unlikable / pleasing \\
\hline 4 & unpleasant / pleasant \\
\hline 5 & attractive / unattractive \\
\hline 6 & friendly / unfriendly \\
\hline
\end{tabular}


(vs 4 in UEQ) was considered to afford better description of users' aesthetic judgement, therefore the attractiveness facet of AttrakDiff was used in current study. All data were collected on $7 p$ Likert scales.

\section{B. Stimuli}

Fig.1 and Fig.2 show the website http://visitestonia.com view for a computer and smart phone. The website's attractiveness was originally tested for design purposes [9]. Current study used the data from two episodes of interaction (with smartphone and computer). First, the participant was passive viewer of interactions happening on the screen, followed by hands on interaction episode. The conditions of the experiment were deployed as follows:

- 30-second video, featuring the essential aspects of website usage, played on smart phone.

- 30-second video, featuring the essential aspects of website usage, played on computer screen.

- Episode of hands on usage according to prepared user task on smart phone

- Episode of hands on usage according to prepared user task on computer

The episode of usage had a pragmatic nature and included information search (finding a restaurant), followed by an action of requesting the information (booking a table in a restaurant). Completion of this task represented well available user actions on given website. For a smart phone, the interactions included slide to scroll, flick to scroll and tap to select where system reaction was intended to be immediate and precise in case of slide and tap gestures, and delayed and approximate in case of flick gesture. For computer interactions, only the mouse was used to navigate the site (keyboard was not needed). All interactions on computer were precise and immediate, however, hovering the mouse over interactive objects induced soft and slightly delayed dynamics such as fade in-out, transparency change, zoom and slight pan.

\section{Participants}

The participants were recruited with respect to two relevant criteria. First, they needed to have sufficient experience (at least weekly use) in browsing the web on both types of devices, computer and smart phone, and second, they should not have been familiar with the website under testing. The number of participants was chosen to be sufficient for valid results.

\section{D. $\quad$ Procedure}

Participants were invited one by one. They were then briefed about upcoming session, informed consent was agreed and demographic data were collected during 5 minutes after arrival. The session took place in lab conditions. A Windows 10 desktop computer with 24 " monitor and iPhone 7 or Nexus 5 smart phones were used in the study. Google Chrome browser for browsing the website on computer, and both smart phones' native browsers were used in order to exclude the influence of browser differences. A more familiar smart phone was chosen according to user's previous experience. Testing phase under all 4 conditions took maximum 30 minutes in total, including also the completion of questionnaires after each condition.

\section{E. Analysis}

Collected data were normalized for better comparison with other similar studies, e.g., for comparing the variability in UX related psychometric scales. Standard deviation was used to assess the consistency of users' perceptions on all ACI-based scales in four different conditions. Further analysis intended

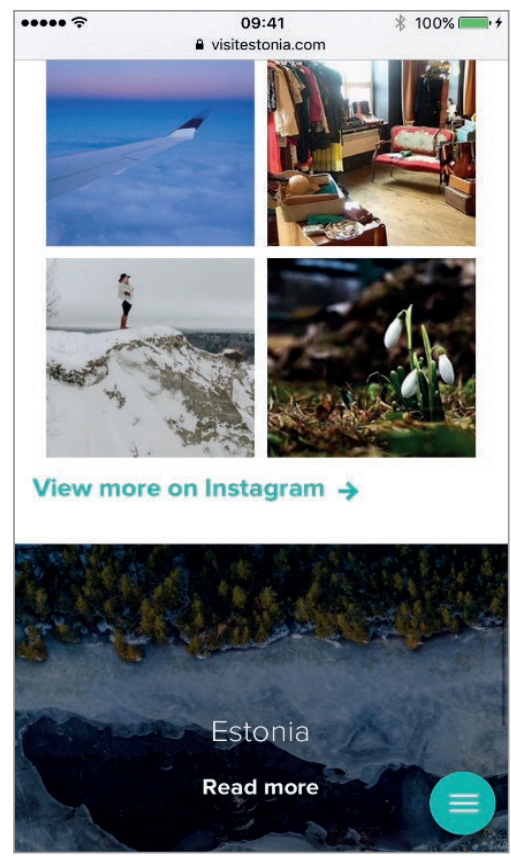

Fig. 1 Screenshot of stimuli on a smartphone

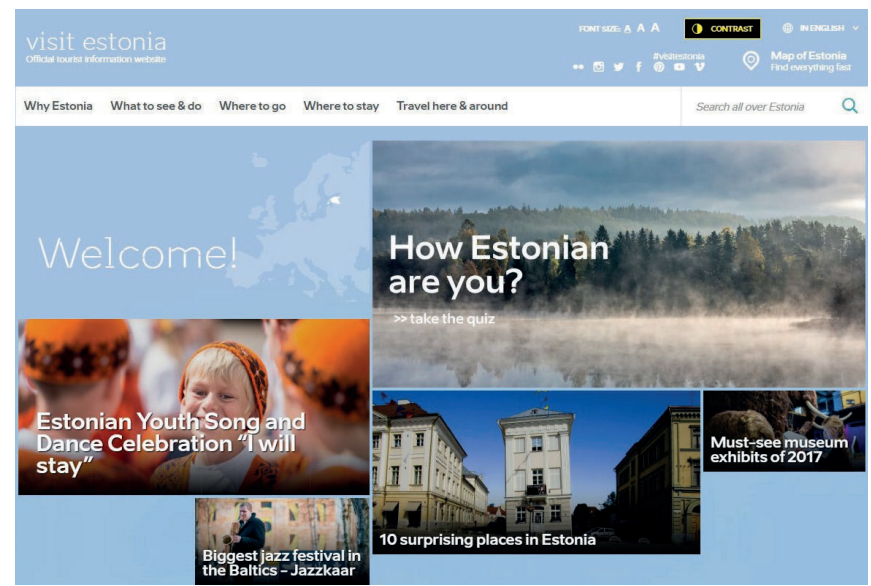

Fig. 2 Screenshot of stimuli on a computer 
to reveal whether aesthetic categories are related to perceived aesthetics of interaction. The Pearson correlation coefficients were calculated between attractiveness and the ACI-based scales. We assumed the attractiveness measure of AttrakDiff questionnaire represents users' perception on aesthetics of interaction. This assumption is based on the authors' expert opinion that five (out of 7) items in attractiveness facet concern users' aesthetic judgment. The significance and the value of correlations was expected to express the aesthetic relevance of different ACI's in various context of use.

\section{RESUlts AND Discussion}

All in all 27 users (11 male) with age ranging from 21 to 59 (average 33.6), participated in an empirical study. The participants first watched 30 second screen videos of the use of http://visitestonia.com and then tested the short interaction episodes on the same website using two different devices: desktop computer and smart phone. Completing the interaction episode took 1:49 $\mathrm{min}$ in average. The values of attractiveness and ACI were collected after each of the four conditions (two interaction episodes and two screen videos). TableIII shows average values and standard deviations of all

TABLE III.

NORMALIZED AVERAGE VALUES AND STANDARD DEVIATIONS OF ATTRAKDIFF ATTRACTIVENESS VALUE AND ACI SCALES. FIRST WORD OF SEMANTIC DIFFERENTIAL STANDS FOR LOWER END OF NORMALIZED SCALE (E.G. BAD=0 AND GOOD=1).

\begin{tabular}{|c|c|c|c|c|c|c|c|c|c|c|}
\hline & \multicolumn{2}{|c|}{$\begin{array}{l}\text { Interaction } \\
\text { computer }\end{array}$} & \multicolumn{2}{|c|}{$\begin{array}{c}\text { Interaction } \\
\text { phone }\end{array}$} & \multicolumn{2}{|c|}{$\begin{array}{c}\text { Video } \\
\text { computer }\end{array}$} & \multicolumn{2}{|c|}{ Video phone } & \multicolumn{2}{|c|}{ Total } \\
\hline & average & st.dev & average & st.dev & average & st.dev & average & st.dev & average & st.dev \\
\hline \multicolumn{11}{|l|}{ AttrakDiff } \\
\hline Attractiveness: unattractive / attractive & 0.75 & 0.17 & 0.62 & 0.18 & 0.75 & 0.14 & 0.67 & 0.14 & 0.70 & 0.17 \\
\hline \multicolumn{11}{|l|}{ ACI } \\
\hline Arousal: exciting / calm & 0.49 & 0.28 & 0.49 & 0.23 & 0.45 & 0.29 & 0.53 & 0.22 & 0.49 & 0.25 \\
\hline Playfulness: playful / serious & 0.45 & 0.21 & 0.48 & 0.22 & 0.40 & 0.20 & 0.39 & 0.20 & 0.43 & 0.21 \\
\hline Dynamics: dynamic / static & 0.36 & 0.24 & 0.43 & 0.23 & 0.29 & 0.18 & 0.38 & 0.25 & 0.37 & 0.23 \\
\hline Fashion: modern / old fashioned & 0.34 & 0.21 & 0.37 & 0.21 & 0.28 & 0.22 & 0.32 & 0.20 & 0.33 & 0.21 \\
\hline Natural realism: natural / unnatural & 0.32 & 0.21 & 0.43 & 0.20 & 0.32 & 0.25 & 0.41 & 0.21 & 0.37 & 0.22 \\
\hline Precision: precise / imprecise & 0.34 & 0.24 & 0.48 & 0.25 & 0.41 & 0.20 & 0.49 & 0.19 & 0.43 & 0.23 \\
\hline Congruence: appropriate / inappropriate & 0.28 & 0.24 & 0.37 & 0.20 & 0.23 & 0.14 & 0.34 & 0.20 & 0.30 & 0.20 \\
\hline Informativeness: informative / arbitrary & 0.22 & 0.22 & 0.38 & 0.30 & 0.24 & 0.21 & 0.32 & 0.24 & 0.29 & 0.25 \\
\hline Personal relatedness: fits me / doesn't fit me & 0.29 & 0.28 & 0.41 & 0.27 & 0.32 & 0.27 & 0.37 & 0.23 & 0.35 & 0.26 \\
\hline Closure: complete / incomplete & 0.36 & 0.23 & 0.50 & 0.25 & 0.36 & 0.22 & 0.51 & 0.20 & 0.43 & 0.24 \\
\hline Complexity: complex / simple & 0.68 & 0.23 & 0.51 & 0.28 & 0.62 & 0.28 & 0.48 & 0.28 & 0.57 & 0.28 \\
\hline Predictability: predictable / unpredictable & 0.37 & 0.25 & 0.49 & 0.23 & 0.41 & 0.24 & 0.47 & 0.22 & 0.44 & 0.24 \\
\hline Controllability: controlled / uncontrolled & 0.35 & 0.19 & 0.43 & 0.22 & 0.33 & 0.21 & 0.41 & 0.24 & 0.38 & 0.22 \\
\hline Time/Speed: fast / slow & 0.25 & 0.22 & 0.33 & 0.20 & 0.26 & 0.23 & 0.23 & 0.26 & 0.27 & 0.23 \\
\hline Delay: immediate / delayed & 0.27 & 0.20 & 0.33 & 0.21 & 0.30 & 0.20 & 0.33 & 0.22 & 0.31 & 0.21 \\
\hline Synaesthesia: synchronized / unsynchronized & 0.34 & 0.19 & 0.41 & 0.18 & 0.36 & 0.14 & 0.41 & 0.20 & 0.38 & 0.18 \\
\hline Smooth mechanics: continuous / stepwise & 0.43 & 0.23 & 0.46 & 0.24 & 0.44 & 0.20 & 0.42 & 0.24 & 0.44 & 0.23 \\
\hline Smooth phrasing: flowing / dripping & 0.33 & 0.20 & 0.43 & 0.22 & 0.31 & 0.22 & 0.33 & 0.22 & 0.35 & 0.22 \\
\hline Force: powerful / gentle & 0.54 & 0.21 & 0.57 & 0.19 & 0.50 & 0.26 & 0.51 & 0.26 & 0.53 & 0.23 \\
\hline Proximity: close / distant & 0.34 & 0.20 & 0.43 & 0.18 & 0.41 & 0.20 & 0.43 & 0.20 & 0.40 & 0.20 \\
\hline Smooth texture: smooth / rough & 0.33 & 0.18 & 0.42 & 0.22 & 0.33 & 0.19 & 0.32 & 0.19 & 0.35 & 0.20 \\
\hline Range: free / limited & 0.38 & 0.24 & 0.45 & 0.25 & 0.37 & 0.21 & 0.43 & 0.25 & 0.41 & 0.24 \\
\hline Dimensionality: 3D / 2D & 0.66 & 0.27 & 0.70 & 0.23 & 0.72 & 0.23 & 0.77 & 0.22 & 0.71 & 0.24 \\
\hline
\end{tabular}


measures for all conditions separately and for a total of all conditions.

\section{A. Diversity of Perceptions}

The standard deviation $(\sigma)$, of reported values of attractiveness across the conditions ranges from $\sigma=0.14$ to $\sigma=0.18$. The same statistic across the scales of ACI ranges: $0.14<\sigma<0.3$. The halfway value of latter range was used as a threshold $(\sigma>0.22)$ to indicate the categories where participants' perceptions were more diverse (highlighted in TableIII). Most distinctive examples of such categories were arousal, personal relatedness, complexity, informativeness, range and dimensionality. We were interested whether the categories were perceived more or less homogeneously across different conditions. Count of more diversely perceived categories was used to analyse differences between conditions. As a result, hands on interactions resulted in more diverse perceptions than watching the videos. At the same time the conditions with interactions (computer and phone) had more or less the same diversity of perceptions. Must also be noted that stimuli were perceived more attractive on computer than on phone in all conditions. Further interest was focused on how differently were ACI perceived during the interactions with computer and phone. Most diverse perceptions were found on informativeness on phone $(\sigma=0.3)$ while the same category had medium diversity $(\sigma=0.22)$ for computer interactions. Congruence, in contrast, was perceived more diversely on computer than on phone. Evaluations on arousal and dimensionality were slightly more diverse on computer while complexity was more diversely perceived on phone.

\section{TABLE IV.}

AESTHETIC CORRELATIONS OF 23 CATEGORIES IN DIFFERENT CONDITIONS. FIRST WORD OF SEMANTIC DIFFERENTIAL STANDS FOR LOWER END OF SCALE (E.G. EXCITING=0 AND CALM=1). ATTRACTIVENESS SCALE IS POSITIONED UNATTRACTIVE=0,AND ATTRACTIVE $=1(* \mathrm{p}<0.05 ; * * \mathrm{p}<0.01)$.

\begin{tabular}{|c|c|c|c|c|}
\hline Aesthetic Category scale / Condition & $\begin{array}{c}\text { Interaction } \\
\text { computer }\end{array}$ & $\begin{array}{c}\text { Interaction } \\
\text { phone }\end{array}$ & $\begin{array}{c}\text { Video } \\
\text { computer }\end{array}$ & Video phone \\
\hline Arousal: exciting / calm & -0.04 & -0.20 & -0.13 & 0.30 \\
\hline Playfulness: playful / serious & -0.23 & -0.08 & -0.12 & -0.16 \\
\hline Dynamics: dynamic / static & $-0.49 * *$ & -0.16 & -0.35 & -0.12 \\
\hline Fashion: modern / old fashioned & $-0.64 * *$ & $-0.53 * *$ & $-0.39 *$ & $-0.58 * *$ \\
\hline Natural realism: natural / unnatural & $-0.85 * *$ & $-0.79 * *$ & $-0.66^{* *}$ & $-0.51 * *$ \\
\hline Precision: precise / imprecise & $-0.41 *$ & $-0.53 * *$ & $-0.63 * *$ & $-0.46^{*}$ \\
\hline Congruence: appropriate / inappropriate & $-0.70 * *$ & $-0.56^{* *}$ & $-0.64 * *$ & $-0.46^{*}$ \\
\hline Informativeness: informative / arbitrary & $-0.75 * *$ & $-0.68 * *$ & $-0.78 * *$ & $-0.69 * *$ \\
\hline Personal relatedness: fits me / doesn't fit me & $-0.80 * *$ & $-0.65 * *$ & $-0.72 * *$ & $-0.64 * *$ \\
\hline Closure: complete / incomplete & $-0.57 * *$ & $-0.61 * *$ & $-0.65 * *$ & $-0.52 * *$ \\
\hline Complexity: complex / simple & $0.55 * *$ & $0.64 * *$ & $0.38 *$ & 0.32 \\
\hline Predictability: predictable / unpredictable & $-0.51^{* *}$ & $-0.57 * *$ & -0.18 & -0.21 \\
\hline Controllability: controlled / uncontrolled & $-0.62 * *$ & $-0.78 * *$ & $-0.43^{*}$ & $-0.52 * *$ \\
\hline Time/Speed: fast / slow & $-0.65 * *$ & $-0.59 * *$ & -0.16 & -0.34 \\
\hline Delay: immediate / delayed & -0.34 & $-0.66^{* *}$ & $-0.58 * *$ & $-0.51 * *$ \\
\hline Synaesthesia: synchronized / unsynchronized & $-0.47 *$ & $-0.40^{*}$ & -0.30 & $-0.41 *$ \\
\hline Smooth mechanics: continuous / stepwise & $-0.43 *$ & $-0.51^{* *}$ & -0.22 & -0.25 \\
\hline Smooth phrasing: flowing / dripping & $-0.51 * *$ & $-0.50 * *$ & $-0.52 * *$ & -0.36 \\
\hline Force: powerful / gentle & 0.26 & -0.20 & -0.10 & 0.17 \\
\hline Proximity: close / distant & $-0.53 * *$ & $-0.71 * *$ & $-0.42 *$ & $-0.48^{*}$ \\
\hline Smooth texture: smooth / rough & $-0.46^{*}$ & $-0.58 * *$ & -0.19 & -0.02 \\
\hline Range: free / limited & $-0.59 * *$ & $-0.71 * *$ & $-0.42 *$ & -0.24 \\
\hline Dimensionality: 3D / 2D & -0.23 & -0.14 & -0.22 & -0.30 \\
\hline
\end{tabular}




\section{B. $\quad$ Aesthetic Correlations}

Next step of the analysis intended to find out how much ACI are capable of explaining the aesthetics of interaction in current conditions. The correlation analysis was applied to reveal relations between ACI and attractiveness measure. Seventeen out of 23 ACI showed significant correlation with perceived attractiveness in both conditions of hands on interactions. The results are presented in TableIV. Four categories were not found correlated to the perceived attractiveness in any of the conditions. These categories were arousal, playfulness, force and dimensionality. Two of these categories (arousal and dimensionality) were perceived rather diversely (see TableIII), which could explain low correlations in corresponding cases. Must be noted that the category of range had high aesthetic correlation despite of higher diversity of perceptions $(\sigma=0.24 \ldots 0.25)$. Low aesthetic correlation of playfulness category, however, could be explained with the pragmatic nature of interactions in given stimuli. Two of the categories did not have significant correlation in both conditions of interaction. The category of dynamics had significant correlation in interactions with computer, while the category of delay had significant correlation only in case of interaction with the phone. Ten of the categories showed significant aesthetic correlations in both conditions of watching the video, which indicates the connection to aesthetics of appearance. According to the significance and value of correlation coefficient, seven of the categories seemed more explicitly related to aesthetics of interaction. These categories are: dynamics, complexity, predictability, speed/time, smooth mechanics, smooth texture and range.

\section{CONCLUSION}

The study addressed users' aesthetic perceptions during interactions with computer and smartphone. This was a follow-up of previously conducted elicitation study of ACI (previous study). Goal of current study was to explore the goodness of ACI. Previous study concluded with uncertain goodness of 10 categories (arousal, dynamics, natural realism, informativeness, personal relatedness, closure, controllability, speed/time, delay and force), suggesting additional research. Previous study also requested for contribution to additional understanding of 6 newly established categories, which were not addressed by prior work (natural realism, congruence, informativeness, closure, smooth texture and dimensionality). The goodness of categories was first assessed via consistency of users' perceptions, expressed by standard deviation. Then the aesthetic relevance, expressed correlation between ACI and attractiveness measure was used to assess the goodness. First we focused on 6 newly established categories. As a result, two out of 6 categories (natural realism, smooth texture) were considered both consistent and aesthetically relevant. Three categories (congruence, informativeness and closure) were partly consistent, but still aesthetically relevant; and one category (dimensionality) was found inconsistent and aesthetically not relevant in current context. Two other categories, found inconsistent in previous study (controllability and speed/time) appeared both consistent and aesthetically relevant, but the categories of force and arousal were found inconsistent and aesthetically not relevant. The categories of dynamics, personal relatedness and delay proved to be aesthetically relevant in some of the tested conditions. Similarly to the initial study, category of playfulness was perceived consistently, but did not show aesthetic correlations in any of tested conditions.

Most of the ACI (20 out of 23) proved to be relevant at least in some of given conditions. Authors suggest further study of all 23 ACI using various context. Further study of ACI is expected to have two main interests. One objective is to study the aesthetics in context of non-pragmatic, pleasureoriented interactions, such as games and interactive art. The other objective is to test ACI in broader selection of different interaction modalities. E. g., motorics of user effort, wider scope of touch and body gestures, interface dynamics, haptics and sound.

Another idea of further study is to explore the use of ACI for informing the design about aesthetically relevant features in interaction. The pattern of diversity of perceptions (similar to the TableIII) could be used to test the design against ACI. I.e., whether the category is distinct in given design. The pattern of aesthetic relevance (similar to the TableIV) could verify how relevant are the categories in a given context. The question to find answer is: how to bind product features to those categories?

\section{REFERENCES}

[1] T. Djajadiningrat, S. Wensveen, J. Frens and K. Overbeeke, "Tangible products: Redressing the balance between appearance and action," Personal and Ubiquitous Computing, 8, 2004. pp. 294-309. http://doi.org/10.1007/ s00779-004-0293-8

[2] L. Hallnäs, J. Redström, "Slow Technology - Designing for Reflection," Personal and Ubiquitous Computing, 5(3), 2001. pp. 201-212. http://doi. org/10.1007/PL00000019

[3] W. N. W. Hashim, N. L. M. Noor, W. A. W. Adnan and F. M. Saman, "Graceful interaction design: Measuring emotional response towards movement quality," International Conference on User Science and Engineering (i-USEr), 2011 pp. 13-17. http://doi.org/10.1109/iUSEr.2011.6150528

[4] W. N. W. Hashim, N. L. M. Noor and W. A. W. Adnan, "A framework for graceful interaction: Applying Laban effort theory to define graceful movement quality," In Proceedings - 2010 International Conference on User Science and Engineering, i-USEr 2010 pp. 139-144. http://doi.org/10.1109/ IUSER.2010.5716739

[5] M. Hassenzahl, "Aesthetics in interactive products: Correlates and consequences of beauty," Product Experience, 2008, 287-302. http://doi. org/10.1016/B978-008045089-6.50014-9

[6] M. Hassenzahl, M. Burmester and F. Koller, "AttrakDiff: Ein Fragebogen zur Messung wahrgenommener hedonischer und pragmatischer Qualität," Mensch \& Computer 2003: Interaktion in Bewegung, pp. 187-196. http://doi.org/10.1007/978-3-322-80058-9

[7] P. Hekkert, "Design aesthetics: principles of pleasure in design," Psychology Science, 48(2), 2006, pp. 157-172. 
[8] E. Karapanos, "Quantifying Diversity in User Experience," unpublished $\mathrm{PhD}$ thesis, Eindhoven University of Technology, 2010.

[9] L. Kukk, "Evaluating user's aesthetic experience during interaction," unpublished master's thesis, Tallinn University, 2017.

[10] R. Laban and F. C. Lawrence, "Effort: economy of human movement," MacDonald and Evans, 2nd Edition, 1973

[11] B. Laugwitz, T. Held and M. Schrepp, "Construction and evaluation of a user experience questionnaire," USAB 2008, LNCS 5298, Springer-Verlag 2008, pp. 63-76.

[12] T. Lavie and N. Tractinsky, "Assessing dimensions of perceived visual aesthetics of web sites," Human-Computer Studies, (60), 2004, pp. 269-298.

[13] E. Lenz, S. Diefenbach and M. Hassenzahl, "Exploring relationships between interaction attributes and experience," In Proc. DPPI 2013, pp. 126 135. http://doi.org/10.1145/2513506.2513520

[14] Y. Lim, S.-S. Lee and K. Lee, "Interactivity attributess: a new way of thinking and describing interactivity," Proceedings of the 27th International Conference on Human Factors in Computing Systems, 2009. http://doi. org/10.1145/1518701.1518719

[15] G. Lindgaard, C. Dudek, D. Sen, L. Sumegi and P. Noonan, "An exploration of relations between visual appeal, trustworthiness and perceived usability of homepages," ACM Trans. Comput.-Hum. Interact., 18(1), 2011. http://doi.org/10.1145/1959022.1959023

[16] J. Löwgren, "Five things I believe about the aesthetics of interaction design," The study of visual aesthetics in human-computer interaction pp. $1-8,2008$.

[17] A. Miniukovich, "Computational aesthetics in HCI: towards a predictive model of graphical user interface," $\mathrm{PhD}$ thesis, University of Trento, 2016.

[18] M. Moshagen, "A short version of the visual aesthetics of websites inventory," Behaviour \& Information Technology, 32(12), 2013, pp. 13051311. http://doi.org/10.1080/0144929X.2012.694910
[19] M. Moshagen and M. Thielsch, "Facets of visual aesthetics," International Journal of Human-Computer Studies, 68(10), 2010, pp. 689709. http://doi.org/10.1016/j.ijhcs.2010.05.006

[20] M. Mõttus, E. Karapanos, D. Lamas and G. Cockton, "Understanding aesthetics of interaction: a repertory grid study," In Proceedings of the 9th Nordic Conference on Human-Computer Interaction (NordiCHI), 2016. http://dx.doi.org/10.1145/2971485.2996755

[21] N. Noor, W. Hashim, W. Wan Adnan and F. Saman, "Mapping graceful interaction design from dance performance," Human-Computer Interaction. Applications and Services SE 29, 2014, Vol. 8512, pp. 301-311. http://doi. org/10.1007/978-3-319-07227-2_29

[22] D. Rocchesso, S. Serafin, F. Behrendt, N. Bernardini, R. Bresin, G. Eckel et al., "Sonic interaction design: sound, information and experience," in extended abstracts on human factors in computing systems, New York, NY, USA: ACM, 2008. pp. 3969-3972. http://doi.org/10.1145/1358628.1358969 [23] T. Schiphorst, N. Motamedi and N. Jaffe, "Applying an aesthetic framework of touch for table-top interactions," in Horizontal Interactive Human-Computer Systems, TABLETOP '07, Second Annual IEEE International Workshop, 2007, pp. 71-74. http://doi.org/10.1109/ TABLETOP.2007.20

[24] A. Sonderegger, J. Sauer and J. Eichenberger, "Expressive and classical aesthetics: two distinct concepts with highly similar effect patterns in userartefact interaction," Behaviour \& Information Technology, 33(11), 2014, pp. 1180-1191. http://doi.org/10.1080/0144929X.2013.853835

[25] A. N. Tuch, S. P. Roth, K. Hornbæk, K. Opwis and J. A. Bargas-Avila, "Is beautiful really usable? Toward understanding the relation between usability, aesthetics, and affect in HCI," Computers in Human Behavior, 28, 2012, pp. 1596-1607. http://doi.org/10.1016/j.chb.2012.03.024

[26] W. N. Wan Hashim, N. L. Md Noor and W. A. Wan Adnan, "The Design of Aesthetic Interaction: Towards a Graceful Interaction Framework," in Icis 2009, pp. 69-75. http://doi.org/10.1145/1655925.1655938 